\title{
The Adrenergic Control of
}

\section{Lower Esophageal Sphincter Function}

\author{
AN EXPERIMENTAL MODEL OF DENERVATION \\ SUPERSENSITIVITY
}

\author{
Anthony J. DiMarino and Sidney Cohen \\ From the Gastrointestinal Section, Department of Medicine, Hospital of the \\ University of Pennsylvania, and Veterans Administration Hospital, \\ Philadelphia, Pennsylvania 19104
}

A в S T R A C T To evaluate the adrenergic regulation of lower esophageal sphincter (LES) function, LES pressure, LES relaxation during swallowing. and blood pressure were measured in the anesthetized opossum, Didelphis virginiana, during intravenous administration of alpha and beta adrenergic agonists and antagonists. Studies were done in controls and animals adrenergically denervated with 6-hydroxydopamine. Alpha adrenergic agonists (norepinephrine. phenylephrine) increased LES pressure and blood pressure, whereas a beta adrenergic agonist (isoproterenol) decreased both pressures. Alpha adrenergic antagonism (phentolamine) reduced basal LES pressure by $38.3 \pm 3.8 \%$ (mean $\pm \mathrm{SEM}) \quad(P<0.001)$. Beta adrenergic antagonism (propranolol) had no significant effect on either basal LES pressure or percent of LES relaxation with swallowing. After adrenergic denervation with 6-hydroxydopamine, basal LES pressure was reduced by $22.5 \pm 5.3 \% \quad(P<0.025)$ but LES relaxation during swallowing was unaltered. In denervated animals, both LES pressure and blood pressure dose response curves showed characteristics of denervation supersensitivity to alpha but not to beta adrenergic agonists. These studies suggest: $(a)$ a significant portion of basal LES pressure is dependent upon alpha adrenergic stimulation; ( $b$ ) LES relaxation during swallowing is not an adrenergically mediated response; (c) the LES pressure response to alpha adrenergic agonists after 6hydroxydopamine may serve as a model of denervation supersensitivity in the gastrointestinal tract.

Received for publication 23 October 1972 and in revised form 23 February 1973.

\section{INTRODUCTION}

The adrenergic innervation of the gastrointestinal tract generally has an inhibitory effect on motor function (1). However, the internal anal (2), choledochal ( 3 , $4)$, ileocecal $(5,6)$, and lower esophageal sphincters (7-9) (LES) ${ }^{1}$ have been shown to have alpha adrenergic receptors, the stimulation of which produces an excitatory effect. Beta adrenergic stimulation at these sphincters still produces an inhibitory response. It had been suggested through studies in vitro that the excitatory response mediated through alpha adrenergic stimulation at the LES may be an important factor in the genesis of sphincter pressure (7). In addition. it had been proposed that the inhibitory response to beta adrenergic stimulation may represent the relaxation in LES pressure during swallowing (10). The purpose of this study was to investigate the adrenergic responses of the LES in the anesthetized opossum and to quantify the role of the adrenergic neural system in the genesis of basal LES pressure and in the inhibitory response to swallowing.

\section{METHODS}

All studies were performed on the adult opossum, species Didelphis virginiana. Animals of both sexes weighing between 2.2 and $3.6 \mathrm{~kg}$ were anesthetized with $2.0 \%$ choralose $\left(3.0 \mathrm{~cm}^{3} / \mathrm{kg}\right)$ and supplemented once with pentobarbital, $10.0 \mathrm{mg}$, during surgery and tube insertion. After successful anesthesia, a heparinized cannula was inserted into the femoral artery and connected to an external transducer (Statham Instruments, Inc., Oxnard, Calif.) for constant

${ }^{1}$ Abbreviation used in this paper: LES, lower esophageal sphincter. 


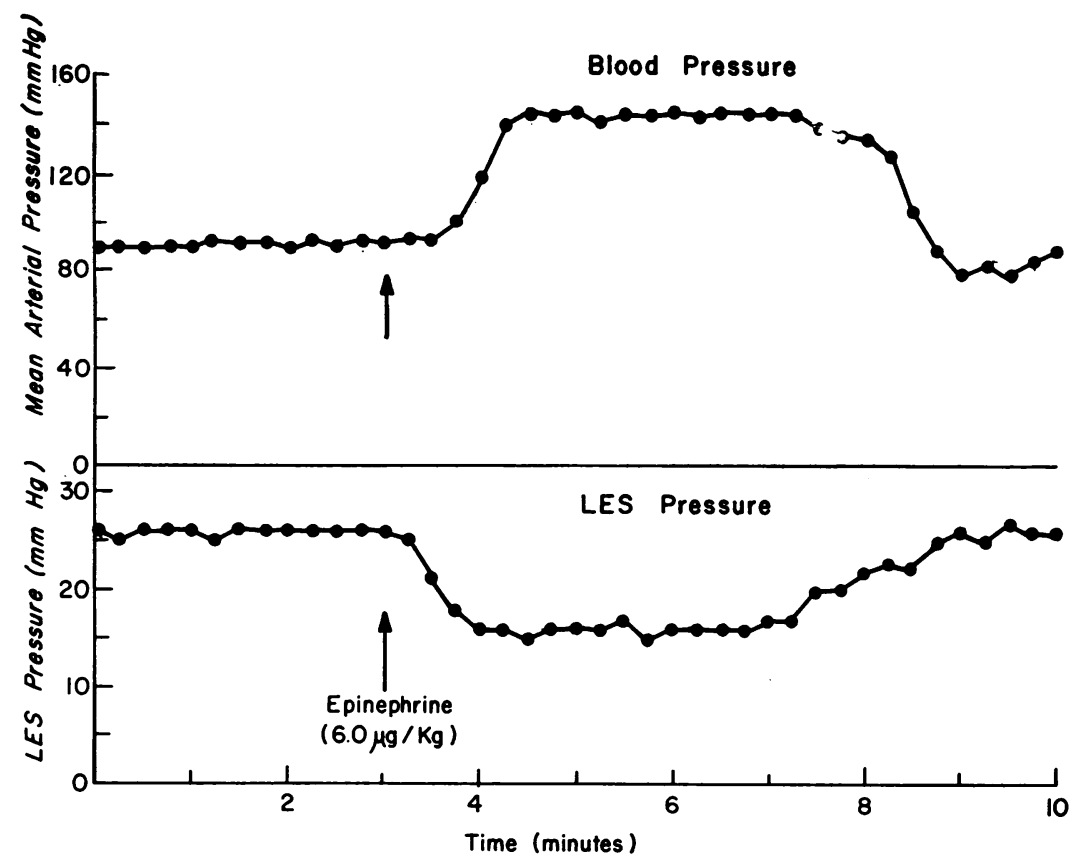

Figure 1 LES pressure and femoral arterial pressure after an intravenous bolus of epinephrine $(6.0 \mu \mathrm{g} / \mathrm{kg})$ in a single animal. After epinephrine, sphincter pressure declined by $38.4 \%$ of its initial level. Simultaneously, mean arterial pressure rose by $61.3 \%$.

blood pressure monitoring. A similar cannula was inserted into the opposite femoral vein for drug administration. Patency of this cannula was maintained through a slow infusion of $0.9 \%$ saline.

Intraluminal pressures were measured through waterfilled polyvinyl catheters, $1.4 \mathrm{~mm} \mathrm{ID}$, connected to external transducers (Statham P23BB) with a linear external calibration of $0-250 \mathrm{~mm} \mathrm{Hg}$. Recording tubes were arranged as a fixed unit with three side orifices, $1.2 \mathrm{~mm}$ in diameter, spaced $5 \mathrm{~cm}$ apart over the distal segment of the tube. Each recording tube was constantly perfused with distilled water by a Harvard infusion pump (Harvard Apparatus Co., Inc., Millis, Mass.) at $1.2 \mathrm{~cm}^{3} / \mathrm{min}$. After insertion into the animal's stomach, the entire recording assembly was withdrawn at $0.5-\mathrm{cm}$ intervals with measurements being recorded at each level for $1 \mathrm{~min}$. For changes in LES pressure in response to drugs, the middle recording orifice was positioned in the sphincter with the proximal lumen in the esophagus and the distal pressure orifice in the stomach. The middle orifice was maintained at the zone of maximal LES pressure by the evaluation of a complete pull-through at each 5-min interval. To evacuate the stomach, gastric aspiration was done through the distal orifice approximately every $30 \mathrm{~min}$. All intraluminal pressures, as well as blood pressure, were graphed on a Beckman rectilinear, ink-writing recorder (Beckman Instruments, Inc., Fullerton, Calif.).

LES pressure was recorded as millimeters of mercury with gastric fundal pressure used as a zero reference. The values were obtained as the midrespiratory value during a 1-min interval from the portion of the sphincter demonstrating the highest pressure. Mean LES pressure was obtained by determining the stable pressure at a minimum of four points during a 1-min period. Blood pressure was measured as the mean pressure obtained over a 1-min interval. Swallowing was induced by gently touching the cricoid cartilage.
Control values of LES pressure, percent of relaxation of the LES with swallowing, and blood pressure were obtained after insertion of the intravenous and intra-arterial cannulas and before the instillation of drugs. A period of $30 \mathrm{~min}$ for stabilization to baseline levels was observed after the administration of each pharmacological agent.

The following pharmacological agents were given intravenously as 30 -s boluses: norepinephrine $(0.025 \mu \mathrm{g} / \mathrm{kg}-$ $72.0 \mu \mathrm{g} / \mathrm{kg})$, isoproterenol $(0.001 \mu \mathrm{g} / \mathrm{kg}-14.0 \mu \mathrm{g} / \mathrm{kg})$, phenylephrine $(55.0 \mu \mathrm{g} / \mathrm{kg})$, and epinephrine $(60 \mu \mathrm{g} / \mathrm{kg})$. The beta adrenergic antagonist, propranolol $(0.2 \mathrm{mg} / \mathrm{kg}-2.0 \mathrm{mg} /$ $\mathrm{kg})$ and the alpha adrenergic antagonist, phentolamine $(0.5$ $\mathrm{mg} / \mathrm{kg}-1.5 \mathrm{mg} / \mathrm{kg}$ ) were also administered. The selections of doses of drugs were initially based on the recognized predictable effects on blood pressure and pulse rates of the animals. Drugs were given in random order and at random doses with agonists and antagonists given on separate days. Each drug was diluted in normal saline and administered as a $2.0-\mathrm{cm}^{3}$ injection. Isoproterenol was diluted in $5 \%$ dextrose and water and given at the same volume.

Sympathetic denervation was obtained with 6-hydroxydopamine at a dose of $100 \mathrm{mg} / \mathrm{kg}$ given intraperitoneally. The compound, 6-hydroxydopamine, had been shown to cause destruction of adrenergic nerves at several anatomic locations (11-14). Previous studies have shown that a single i.p. injection of $16.5 \mathrm{mg} / \mathrm{kg}$ of 6-hydroxydopamine produced adrenergic nerve destruction, which was maximal at $24 \mathrm{~h}$ and lasted for several weeks (12). All studies were performed $24-96 \mathrm{~h}$ after i.p. injection. In eight animals, the mean LES pressure and the percent relaxation in LES pressure during swallowing was noted both before and after 6-hydroxydopamine injection in the same animal.

An evaluation of the extent of adrenergic nerve destruction was made in two ways. First, the LES pressure was measured during the 30 -s i.v. injection of the indirect-acting 


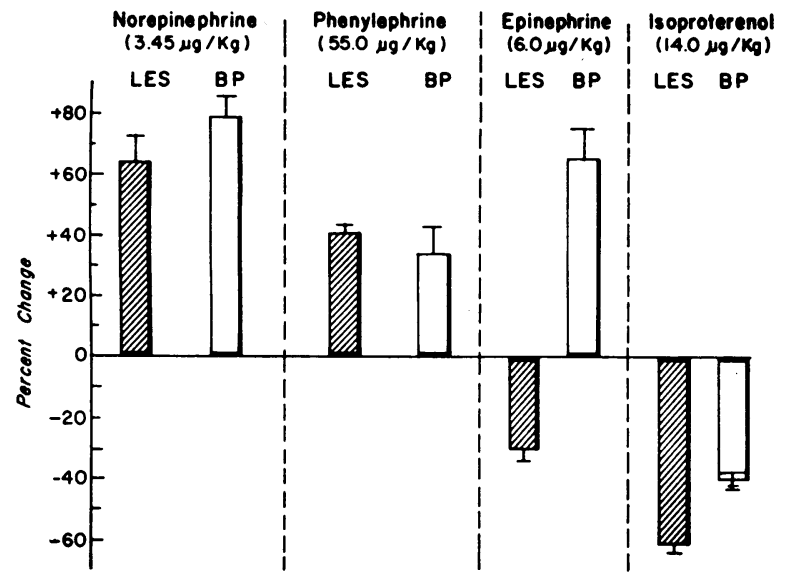

Figure 2 Percent change in LES pressure and femoral arterial blood pressure (BP) in response to adrenergic agonists. Each bar represents the mean \pm SEM for responses measured in a minimum of 10 animals. Phenylephrine and norepinephrine, drugs acting predominantly at alpha adrenergic receptors, increased both LES pressure and arterial pressure. Epinephrine, a compound that acts at both alpha and beta receptors, increased arterial pressure but lowered LES pressure. Isoproterenol, a beta adrenergic stimulant, lowered both LES pressure and arterial pressure. All responses were highly significant. $(P<0.01)$.

amine, tyramine, at doses of $0.04 \mathrm{mg} / \mathrm{kg}, 0.08 \mathrm{mg} / \mathrm{kg}$, and $0.4 \mathrm{mg} / \mathrm{kg}$ in three controls and in three animals given 100 $\mathrm{mg} / \mathrm{kg}$ of 6-hydroxydopamine. The response to tyramine assessed the release of norepinephrine at the LES. Second, esophageal and gastric muscle from four controls and four animals given 6-hydroxydopamine $24-96 \mathrm{~h}$ before killing was assayed directly for norepinephrine. The norepinephrine content was measured using the techniques of Goldman and Jacobowitz $(12,13)$.

Since a major determinant of LES pressure is endogenous gastrin, the effect of adrenergic agents upon serum gastrin levels was evaluated. In five animals, the basal serum gastrin level and the gastrin levels after 6-hydroxydopamine and norepinephrine were determined by the standard doubleantibody technique as utilized previously in this animal model (15). In addition, the LES response to exogenous gastrin I (residue 2-17, Hexadecapeptide amide, Imperial Chemical Industries Ltd., Alderley Park, Cheshire, England) was evaluated in five control animals and in five animals given 6-hydroxydopamine. The dose of gastrin I shown previously to give a maximal LES response was used (15). Gastrin was administered as a single 30 -s intravenous injection. test.

Statistical analysis was performed using the Student $t$ -

\section{RESULTS}

In 31 animals intraluminal manometry demonstrated the presence of a $1.5 \pm 0.2-\mathrm{cm}$ (mean $\pm \mathrm{SEM}$ ) zone of elevated pressure at the junction of esophagus and stomach. The mean midrespiratory pressure within this zone was $36.3 \pm 3.1 \mathrm{~mm} \mathrm{Hg}$ above intra-abdominal pressure. A consistent decrease in pressure was recorded from this zone when deglutition was initiated. This zone of elevated pressure represented the LES.

In Fig. 1 are shown the simultaneous measurements of LES, and arterial pressure in a single animal during the 30 -s intravenous injection of epinephrine. As blood pressure rose from 90 to $145 \mathrm{~mm} \mathrm{Hg}$, LES pressure fell from $26 \mathrm{~mm} \mathrm{Hg}$ to $16 \mathrm{~mm} \mathrm{Hg}$. This response represented a $61.3 \%$ rise in blood pressure and a $38.4 \%$ decrease in LES pressure.

In Fig. 2, the LES and blood pressure responses for 10 animals are summarized. These responses differed for drugs with pure alpha effect (phenylephrine), predominantly alpha effect (norepinephrine), pure beta effect (isoproterenol), and a mixed effect (epinephrine). These studies indicated that drugs acting at alpha receptors increased both LES and blood pressure whereas drugs acting at beta receptors gave an opposite effect. These studies demonstrated the general nature of the response to each type of compound, and that changes in blood pressure and LES pressure can be dissociated, as with epinephrine. The magnitude of the response, as determined with random doses of each agent, cannot be compared for relative potency. Full dose response curves for norepinephrine and isoproterenol were performed and are shown in conjunction with the studies in denervated animals.

After the demonstration of changes in LES pressure to alpha and beta adrenergic agonists, the net endoge-

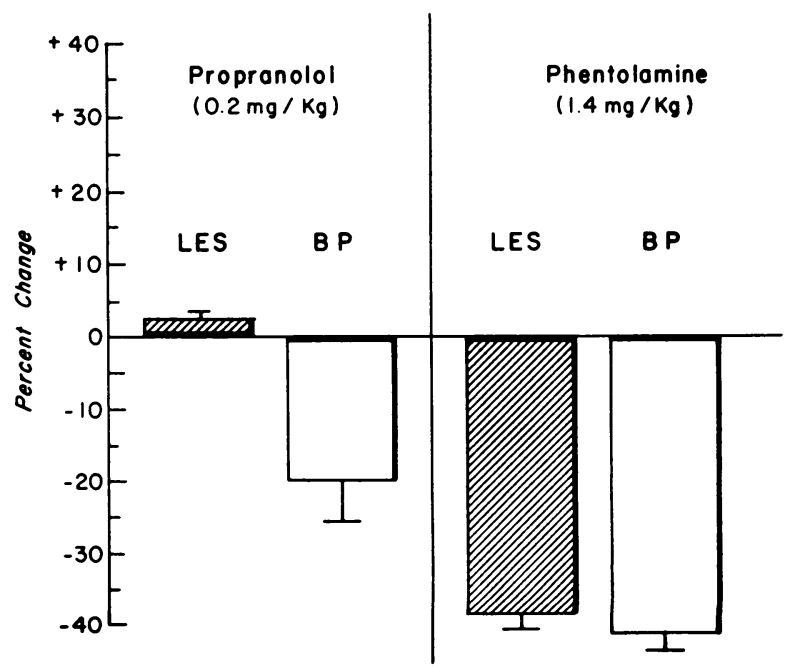

FIgUre 3 Percent change in LES pressure and blood pressure in response to an alpha adrenergic antagonist (phentolamine) and a beta adrenergic antagonist (propranolol). Each bar represents the mean $\pm S E M$ for responses measured in a minimum of 10 animals. Propranolol gave a decrease in blood pressure (BP) $P<0.01$, and a slight increase in LES pressure, $P>0.05$. Phentolamine gave a significant decrease in both $\mathrm{BP}$ and LES pressure ( $P$ $<0.01)$. 
nous adrenergic effect at each receptor was evaluated in the resting anesthetized anımal. In Fig. 3 are shown the LES pressure and blood pressure changes in response to a beta adrenergic antagonist (propranolol) and an alpha adrenergic antagonist (phentolamine). Each compound was administered at a dose selected to abolish totally the response to its natural agonist at the lowest dose shown to give a maximal response. Propranolol gave an increase in LES pressure and a decrease in blood pressure. The change in LES pressure was not significant. Phentolamine gave a reduction in both LES and blood pressure. The LES pressure fell from $31.3 \pm 3.1 \mathrm{~mm} \mathrm{Hg}$ to $19.3 \pm 3.0 \mathrm{~mm} \mathrm{Hg}$, a 38.3 $\pm 3.8 \%$ reduction $(P<0.001)$. Neither antagonist altered the percent reduction in LES pressure in response to swallowing. The decrease in LES pressure upon swallowing was $93.1 \pm 2.2 \%$ before drug administration, $94.6 \pm 3.1 \%$ after phentolamine, and $95.2 \pm 2.9 \%$ after propranolol $(P>0.05)$. Thus, it seemed that basal LES pressure was partially dependent upon alpha adrenergic stimulation, but an adrenergic mechanism did not cause LES relaxation during swallowing.

To evaluate the adrenergic regulation of the LES further, eight animals were studied before and after sympathetic denervation with 6-hydroxydopamine. After the administration of 6-hydroxydopamine, LES pressure was reduced from $39.6 \pm 4.4 \mathrm{~mm} \mathrm{Hg}$ to $30.7 \pm 2.3$ $\mathrm{mm} \mathrm{Hg}$, as shown in Fig. 4 . This $22.5 \pm 5.3 \%$ reduction in LES pressure was statistically significant $(P<$ $0.025)$. After 6-hydroxydopamine the percent relaxation during swallowing was unaltered $(P>0.05)$. Thus, destruction of the adrenergic nerves by 6-hydroxydopamine gave a small reduction in resting LES pressure and no alteration in the LES response to swallowing. However, the decrease in LES pressure after 6-hydroxydopamine was significantly less than that obtained after intravenous phentolamine $(P<0.01)$. The discrepancy in the magnitude of response to 6-hydroxydopamine and phentolamine $(1.5 \mathrm{mg} / \mathrm{kg})$ was not readily explained. Two possibilities were considered. First, an acquired supersensitivity to adrenergic stimulation through circulating catecholamines after denervation may account for the greater reduction in LES pressure with phentolamine. Second, the 6-hydroxydopamine produced only a partial destruction of adrenergic nerves with the esophagus. Each possibility was studied.

In Fig. 5 are shown the dose response curves for both LES and blood pressure to norepinephrine in controls and animals given 6-hydroxydopamine. The LES response to norepinephrine in denervated animals was more sensitive than in controls. The threshold response and the steeply sloped linear portion of the dose response curve was shifted to the left. The maximal
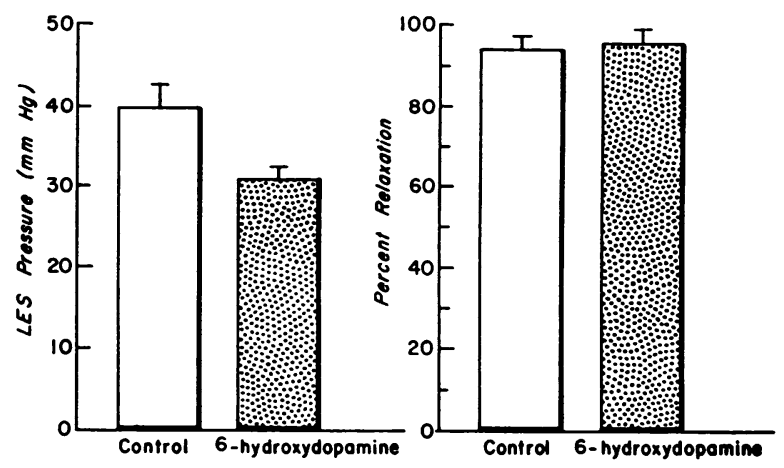

FIGURE 4 LES pressure in millimeters of mercury and percent decrease in LES pressure in response to swallowing. Each bar represents the mean \pm SEM for eight animals studied before and after adrenergic denervation with 6hydroxydopamine. After 6-hydroxydopamine, basal LES pressure was reduced by $8.9 \pm 2.1 \mathrm{~mm} \mathrm{Hg}(P<0.025)$. The percent decrease in LES pressure during swallowing was not significantly affected.

change in LES pressure in control animals, 114.0 $\pm 15.6 \%(33.1 \pm 4.4 \mathrm{~mm} \mathrm{Hg})$ did not differ significantly from the maximal increase in LES pressure in 6hydroxydopamine-treated animals, $117.1 \pm 25.3 \% \quad(35.2$ $\pm 7.6 \mathrm{~mm} \mathrm{Hg}$ ). The blood pressure dose response curve showed similar characteristics of supersensitivity in denervated animals as compared to controls. The maximal rise in blood pressure in controls, $176.1 \pm 41.4 \%$ $(126.8 \pm 29.8 \mathrm{~mm} \mathrm{Hg}$ ), did not differ from the change in blood pressure in 6-hydroxydopamine-treated animals, $202.3 \pm 52.3 \%(105.4 \pm 27.3 \mathrm{~mm} \mathrm{Hg})$. Thus, the reduction in LES pressure after 6-hydroxydopamine may be diminished by an increased sensitivity to catecholamines. In six denervated animals, phentolamine $(1.5 \mathrm{mg} / \mathrm{kg})$ reduced LES pressure by $18.6 \pm 3.2 \%$ $(P<0.01)$, suggesting that an adrenergic effect was still present at the LES.

To determine the effect of denervation on beta adrenergic stimulation, animals treated with 6-hydroxydopamine were evaluated in response to isoproterenol. As shown in Fig. 6, the LES and blood pressure dose response curves were unaltered after denervation. At each dose of isoproterenol, the percents of reduction in both LES pressure and blood pressure were similar.

The above studies with 6-hydroxydopamine demonstrated the dose response characteristics of the LES to be consistent with a denervation supersensitivity for alpha but not beta adrenergic agonists. However, these findings did not resolve the question as to whether the discrepancy in the reduction in basal LES pressure after 6-hydroxydopamine and phentolamine was due to 

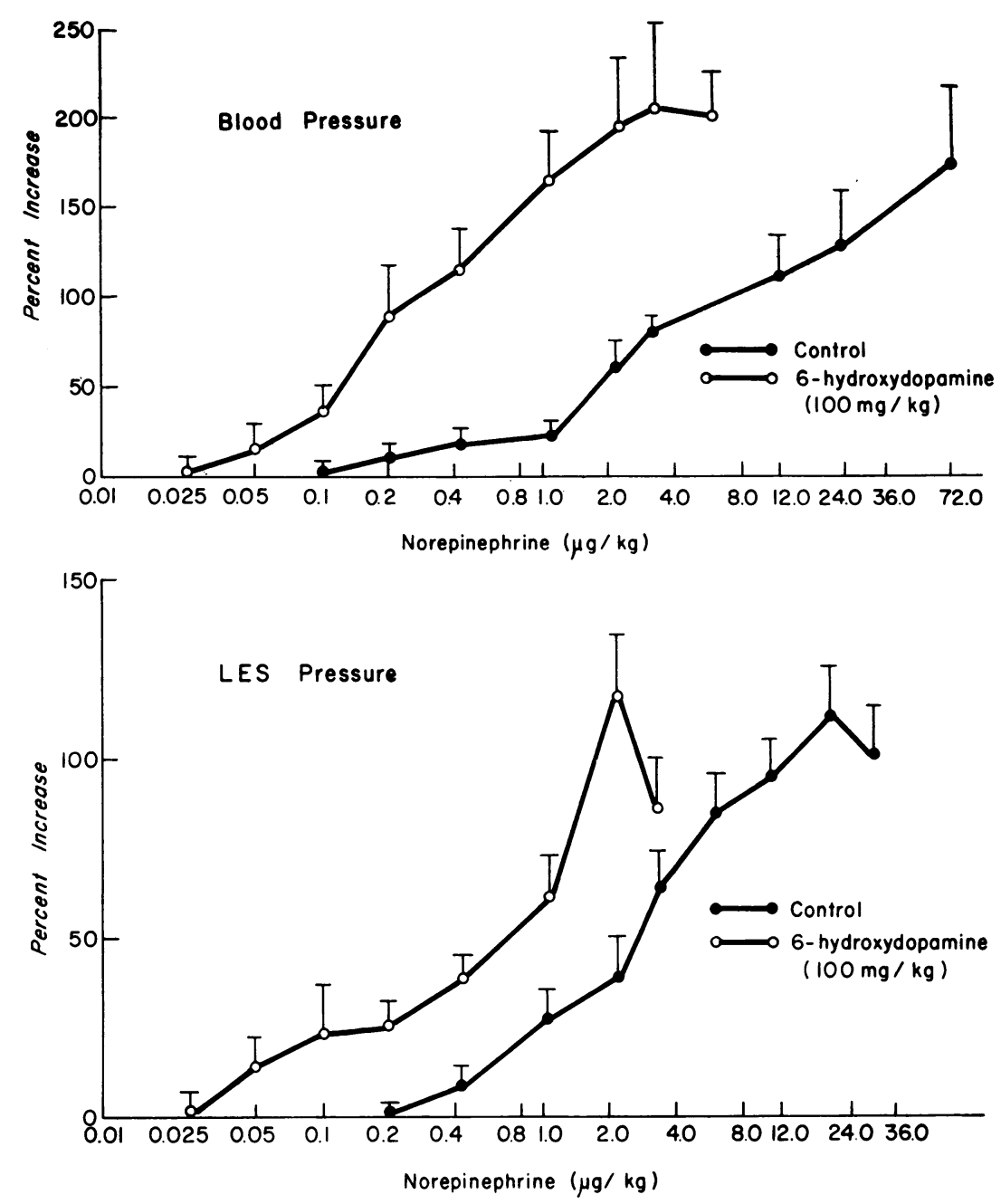

FigURE 5 Norepinephrine dose-response curves for LES pressure and arterial pressure in controls and animals given 6-hydroxydopamine. Each point represents the mean $\pm \mathrm{SEM}$ of the percent change in pressure for eight animals. In animals given 6-hydroxydopamine, the entire LES and arterial pressure dose-response curves were shifted to the left. The threshold and maximum response occurred at lower doses in denervated animals. The maximal percent increases in both LES and blood pressure were similar. The dose of norepinephrine that gave a response equal to half of the maximal response (effective dose 50 ) was lowered significantly for both the LES and blood pressure responses in animals given 6-hydroxydopamine. ( $P$ $<0.01$.)

the acquired supersensitivity or to partial adrenergic nerve destruction. The extent of adrenergic nerve destruction was evaluated by the response to tyramine in vivo and the direct assessment of norepinephrine in the tissue, in vitro.

In three control animals, tyramine, $0.04 \mathrm{mg} / \mathrm{kg}$ and $0.08 \mathrm{mg} / \mathrm{kg}$, gave a $5.5 \pm 0.9 \mathrm{~mm} \mathrm{Hg}(15.3 \pm 0.2 \%)$ and $7.2 \pm 0.9 \mathrm{~mm} \mathrm{Hg}(19.9 \pm 0.2 \%)$ increase in LES pressure, respectively. In three animals given 6-hydroxydopamine, a similar dose of tyramine gave a minus 1.1 $\pm 0.4 \mathrm{~mm} \mathrm{Hg}(3.6 \pm 0.1 \%)$ and a minus $1.6 \pm 0.3 \mathrm{~mm}$ $\mathrm{Hg}(5.2 \pm 0.1 \%)$ change in LES pressure. The response to tyramine achieved statistical significance only in control animals $(\mathrm{P}<0.01)$. Animals given 6-hydroxydopamine were tested further with tyramine $(0.4 \mathrm{mg} / \mathrm{kg})$ with no significant increase in pressure. These findings suggest that in animals given 6-hydroxydopamine, tyramine, an indirect acting agent that releases norepinephrine, could not elicit an increase in LES pressure.

The direct assay of the tissue for norepinephrine showed that in four control animals, the distal esophageal musculature had a norepinephrine content of 0.455 $\pm 0.03 \mu \mathrm{g} / \mathrm{g}$ of tissue as compared to $0.021 \pm 0.005$ $\mu \mathrm{g} / \mathrm{g}$ of tissue in the animals given 6-hydroxydopa- 

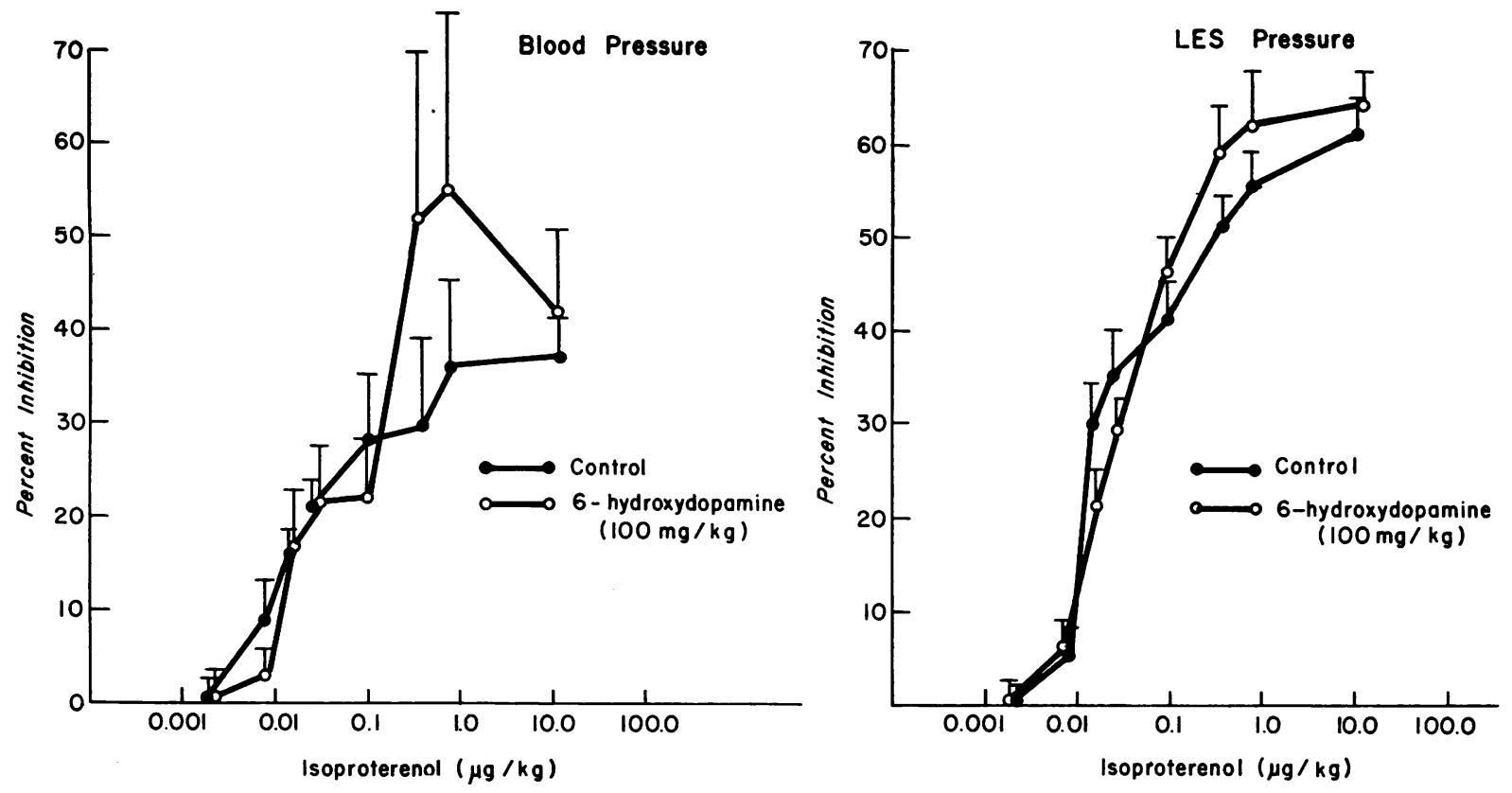

FIGURE 6 Isoproterenol dose response curves for LES pressure and arterial blood pressure in controls and animals given 6-hydroxydopamine. Each point represents the mean $\pm S E M$ of the percent change in pressure for eight animals. The dose-response curves for both LES pressure and blood pressure in denervated animals were similat to controls at each dose.

mine $(P<0.01)$. Thus, tissue norepinephrine was reduced to $4.7 \%$ of control after 6-hydroxydopamine. This magnitude of change was reported previously in tissues demonstrated to have a high degree of nerve destruction (12).

The serum gastrin level in five control animals was $162.3 \pm 18.6 \mathrm{pg} / \mathrm{ml}$, as compared with $158.7 \pm 20.3 \mathrm{pg} / \mathrm{ml}$ in five animals given 6-hydroxydopamine $(P>0.05)$. The basal serum gastrin level of $162.3 \pm 18.6 \mathrm{pg} / \mathrm{ml}$ was decreased to $144.9 \pm 24.6 \mathrm{pg} / \mathrm{ml}$ after the intravenous administration of norepinephrine, $3.5 \mu \mathrm{g} / \mathrm{kg}(P>0.05)$. The maximal LES response to exogenous gastrin $I$ at $1.0 \mu \mathrm{g} / \mathrm{kg}$ was similar in controls, $83.2 \pm 10.1 \mathrm{~mm} \mathrm{Hg}$, as obtained in animals given 6-hydroxydopamine, 79.5 $\pm 9.6 \mathrm{~mm} \mathrm{Hg}(P>0.05)$. These findings suggested that neither 6-hydroxydopamine nor exogenous norepinephrine changed the level of endogenous gastrin. Adrenergic denervation did not alter the LES response to exogenous gastrin $\mathrm{I}$.

\section{DISCUSSION}

The action of adrenergic compounds on esophageal and LES smooth muscle had been previously investigated in vitro (7-9). The unique effect of alpha adrenergic stimulation of esophageal muscle and the greater sensitivity of LES muscle to alpha adrenergic agents suggested that these nerves may play a major role in the genesis of sphincter pressure (7). In addition, it had been suggested that beta receptor stimulation mediated sphincteric relaxation during swallowing (10). The purpose of this study was to investigate the adrenergic responses of the LES and to quantify the role of the adrenergic neural system in the genesis of LES pressure and in the inhibitory response to swallowing. The results of these studies suggested: $(a)$ the alpha adrenergic receptors of the LES mediated contraction whereas the beta receptors mediated inhibition, and both responses were dose-related; $(b)$ in the basal state, a significant portion of LES pressure was dependent upon alpha adrenergic stimulation, but beta adrenergic responses had no role in either basal LES pressure or LES relaxation during swallowing; (c) adrenergic denervation with 6-hydroxydopamine produced a supersensitivity to alpha but not beta adrenergic stimulation.

Although the response of esophageal muscle to adrenergic compounds had been studied in vitro (7-9), the contribution of the adrenergic neural system to the genesis of basal LES pressure was undetermined by accurate recording techniques and pharmacological intervention. In an extensive review of the older literature, nonpharmacological studies of adrenergic effects on the esophagus in a variety of species gave conflicting results (16). However, most studies did indicate that sympathetic nerve stimulation gave "spasm" of the LES in man, monkey, dog, and cat. Conversely, sympathectomy or stellate ganglion block could produce a 
patulous distal esophagus. Clear-cut findings were not agreed upon in all studies (16). More recent studies in vivo suggested that $\mathrm{LES}$ competence was due mainly to endogenous gastrin (15). Passive transfer of gastrin antiserum reduced LES pressure to approximately $20 \%$ of its basal level. The data provided by this study suggested that a smaller portion of basal LES pressure was dependent upon adrenergic nerve function.

Initially, we felt that adrenergic nerve destruction with 6-hydroxydopamine would allow accurate quantification of that portion of LES pressure mediated through adrenergic nerves. However, the findings after 6-hydroxydopamine must be interpreted cautiously. First, the LES response to exogenous norepinephrine, but not to isoproterenol, was increased in sensitivity after 6-hydroxydopamine. Thus, any change in LES pressure after 6-hydroxydopamine might be modified by an increased responsiveness to circulating catecholamines. Second, it was possible that the 6-hydroxydopamine caused only partial adrenergic nerve destruction. After 6-hydroxydopamine, LES pressure was reduced significantly by $22.5 \%$. This reduction in pressure was less than the $38.3 \%$ reduction seen with phentolamine in control animals. A remaining adrenergic-dependent component of LES pressure in the animals given 6-hydroxydopamine was demonstrated by the $18.6 \%$ further decrease in LES pressure with phentolamine. The design of this study did not distinguish directly whether the remaining adrenergic-dependent component of LES pressure after 6-hydroxydopamine was due to the acquired alpha adrenergic supersensitivity or to partial adrenergic nerve destruction. The question was approached by studying the response to tyramine and determining the norepinephrine content of the distal esophagus. Tyramine is an indirect-acting amine that acts to release norepinephrine from nerve terminals. The absence of a response to tyramine has been used as an index of postganglionic denervation or norepinephrine depletion by reserpine $(17,18)$. In the animals given 6-hydroxydopamine, the LES response to tyramine was absent as compared to controls, suggesting a high degree of adrenergic nerve destruction. Further support was obtained by demonstrating that the norepinephrine content of the tissue was reduced to $4.6 \%$ of the control value. These studies suggest a high degree of adrenergic nerve destruction in 6-hydroxydopamine-treated animals but do not prove that the remaining adrenergic-dependent component of LES pressure in denervated animals is due to supersensitivity to circulating catecholamines.

The magnitude of the reduction in LES pressure by phentolamine in control and denervated animals suggested a greater effect of the adrenergic system in the genesis of LES pressure than would be predicted from the study utilizing gastrin antiserum (15). However, the possibility that phentolamine may have antagonist effects other than at alpha receptors could not be excluded (19). Although the studies with phentolamine and 6-hydroxydopamine demonstrated a role for adrenergic nerves in the genesis of basal LES pressure, its exact quantification was difficult to establish.

This study showed that adrenergic nerves did not cause relaxation of the LES during swallowing. After propranolol and denervation with 6-hydroxydopamine, LES relaxation was unaltered. This finding supported the observations in vitro suggesting that LES relaxation during swallowing was mediated through nonadrenergic inhibitory nerves (20).

Although these studies were designed to evaluate the influence of adrenergic nerves on LES function, the intravenous administration of each adrenergic agonist and antagonist also affected cardiovascular function. Changes in blood pressure were noted with each compound. The effect of these changes in blood pressure upon LES pressure was not readily ascertained. However, since blood pressure and LES pressure could be oppositely affected with certain compounds, change in LES pressure could not be attributed solely to alteration in blood pressure.

After 6-hydroxydopamine a change in sensitivity of the LES and blood pressure was recorded in response to norepinephrine but not isoproterenol. Adrenergic supersensitivity of muscle had been investigated extensively in the nictitating membrane of the cat but little work had been done on gastrointestinal smooth muscle in vivo $(17,18)$. The classical studies on adrenergic denervation indicated that there were two specific types of supersensitivity, preganglionic and postganglionic. Since 6-hydroxydopamine destroyed adrenergic nerve terminals, the postganglionic type was the most appropriate model. Postganglionic denervation supersensitivity was shown to appear $24 \mathrm{~h}$ after neural destruction and was characterized by changes in the dose response curve to an alpha adrenergic agonist. The entire curve was shifted to lower concentrations (i.e, to the left) but remained parallel to the control dose response curve. The maximum response was unchanged. In our studies, the norepinephrine dose response curves for LES and blood pressure were also shifted to the left, and the maximum response after denervation was also unchanged. Thus, the change in dose response characteristics after denervation strongly suggested supersensitivity to norepinephrine similar to that found by Trendelenburg in postganglionic denervation of the cat nictitating membrane $(17,18)$. It was of interest that a change in sensitivity to isoproterenol after denervation was not noted. Failure to observe a change in sensitivity to adrenergic inhibition in the gastrointes- 
tinal tract had been reported previously $(18,21)$. The change in sensitivity to norepinephrine after 6-hydroxydopamine as shown here provides the first evidence (to our knowledge) of adrenergic denervation supersensitivity in the esophagus.

The demonstration of the LES dose response characteristics of denervation supersensitivity to norepinephrine at 24-96 h after 6-hydroxydopamine further supported the presence of adrenergic nerve destruction within the esophagus. Although the dose response curves were constructed at the time of predicted maximum adrenergic nerve destruction by a single injection of 6-hydroxydopamine, this brief latent period probably did not allow the maximum development of supersensitivity $(17,18)$. Postganglionic denervation supersensitivity appears at $24 \mathrm{~h}$ but maximum supersensitivity may not be achieved until 1-2 wk later. This is the time required for the additive effect of the small preganglionic (decentralization) component of supersensitivity. To study the prolonged effect of denervation, further studies would be required, using repeated doses of 6-hydroxydopamine to maintain denervation. A comparison of the LES-norepinephrine dose response curve at 24-96 $\mathrm{h}$ with the curve obtained at the later date would then allow quantification of the added preganglionic component of supersensitivity.

\section{ACKNOWLEDGMENTS}

The authors wish to thank Mrs. Fe Green for her careful technical assistance.

This work was supported by Clinical Investigator Funds, Veterans Administration and Training Grant T01-AM5462-06, and Research Grant 1 R01 AM 16280-01, and a Research Career Development Award 1 K4 AM 70, 576-01, National Institutes of Health.

\section{REFERENCES}

1. Daniel, E. E. 1968. Pharmacology of the gastrointestinal tract. Handb. Physiol. 4(Sect. 6) : 2267.

2. Kerremans, R., and R. Penninckx. 1970. A study in vivo of adrenergic receptors in the rectum and in the internal anal sphincter of the cat. Gut. 11: 709.

3. Tansy, M. F., R. C. Mackowak, and R. B. Chaffee. 1971. A vagosympathetic pathway capable of influencing common bile duct motility in the dog. Surg. Gynecol. Obst. 1.33 : 1.

4. Crema, A., G. Benzi, G. Frigo, and F. Bertè. 1965. Occurrence of $\alpha$ - and $\beta$-receptors in the bile duct. Proc. Soc. Exp. Biol. Med. 120: 158.
5. Reynolds, D., G. Demaree, and M. Heiffer. 1967. An excitatory adrenergic alpha receptor mechanism of terminal guinea pig ileum. Proc. Soc. Exp. Biol. Med. $125: 73$.

6. Gazet, J., and R. Jarrett. 1964. The ileocaeco-colic sphincter. Studies in vitro in man, monkey, cat, and dog. Br. J. Surg. 51 : 368.

7. Christensen, J. 1970. Pharmacological identification of the lower esophageal sphincter. J. Clin. Invest. 49: 681.

8. Christensen, J., and R. F. Dons. 1968. Regional variations in response of cat esophageal muscle to stimulation with drugs. J. Pharmacol. Exp. Ther. 161: 55.

9. Christensen, J., and E. E. Daniel. 1968. Effects of some autonomic drugs on circular esophageal smooth muscle. J. Pharmacol. Exp. Ther. 159: 243.

10. Misiewicz, J. J., S. L. Waller, P. P. Anthony, and J. W. P. Gummer. 1969. Achalasia of the cardia: pharmacology and histopathology of isolated cardiac sphincteric muscle from patients with and without achalasia. J. Med. $38: 17$.

11. Brus, R., M. Hess, and D. Jacobowitz. 1970. Effect of 6-hydroxydopamine and thyroxine on chronotropic response to norepinephrine. Eur. J. Pharmacol. 10: 323.

12. Goldman, H., and D. Jacobowitz. 1971. Correlation of norepinephrine content with observations of adrenergic nerves after a single dose of 6-hydroxydopamine in the rat. J. Pharmacol. Exp. Ther. 176: 119.

13. Jacobowitz, D., T. Cooper, and H. B. Barner. 1967. Histochemical and chemical studies of the localization of adrenergic and cholinergic nerves in normal and denervated cat hearts. Circ. Res. 20: 289.

14. Gosling, J. A., and J. S. Dixon. 1972. The effect of 6hydroxydopamine on nerves in the rat upper urinary tract. J. Cell Sci. 10: 197.

15. Lipshutz, W., W. Hughes, and S. Cohen. 1972. The genesis of lower esophageal sphincter pressure: its identification through the use of gastrin antiserum. J. Clin. Invest. 51 : 522 .

16. Ingelfinger, F. 1958. Esophageal motility. Physiol. Rev. $38: 533$.

17. Trendelenburg, U. 1963. Supersensitivity and subsensitivity to sympathomimetric amines. Pharmacol. Rev. 15: 225.

18. Trendelenburg, U. 1966. Mechanisms of supersensitivity and subsensitivity to sympathomimetric amines. Pharmacol. Rev. 18 : 629.

19. Goodman, L., and A. Gilman, editors. 1970. The Pharmacological Basis of Therapeutics. Macmillan \& Co., Ltd., London.

20. Tuch, A., and S. Cohen. 1973. Lower esophageal sphincter relaxation: studies on the neurogenic inhibitory mechanism. J. Clin. Invest. 52: 14.

21. Govier, W. C., M. F. Sugrue, and P. A. Shore. 1969. On the inability to produce supersensitivity to catecholamines in intestinal smooth muscle. J. Pharmacol. Exp. Ther. 165 : 71. 